\title{
BIL\&GIN: A neuroimaging, cognitive, behavioral, and genetic database for the study of human brain lateralization
}

\author{
B.Mazoyer, E.Mellet, G.Perchey, L.Zago, F.Crivello, G.Jobard, N.Delcroix, M.Vigneau, \\ G.Leroux, L.Petit, M.Joliot, N.Tzourio-Mazoyer
}

CNRS UMR5296 Groupe d'Imagerie Neurofonctionnelle, Bordeaux, France

CEA UMR5296 Groupe d'Imagerie Neurofonctionnelle, Bordeaux, France

Université de Bordeaux, UMR5296 Groupe d'Imagerie Neurofonctionnelle, Bordeaux, France

\begin{abstract}
We report on a database, named BIL\&GIN, designed for investigating the cognitive, behavioral, genetic, and brain morphological/functional correlates of hemispheric specialization. The database contains records from a sample of 453 adult participants enriched in left-handers $(45 \%, \mathrm{~N}=205)$ as compared to the general population. For each subject, socio-demographic data, hand and eye laterality, family handedness, and cognitive abilities in the language, motor, visuo-spatial, and numerical domains have been recorded. T1-MRI and DTI data were also acquired, as well as resting-state functional MRI. Task-evoked functional MRI was performed in a sub-sample of 303 subjects ( 157 left-handers) using a customized functional battery of 16 cognitive tasks exploring the same three cognitive domains.

Performances at the tasks executed in the magnet as well as post-acquisition debriefing were recorded. A saliva sample was obtained from the subjects of this sub-sample from which DNA was extracted. The BIL\&GIN contains results of imaging data processing for each subject, namely maps of tissue (GM, WM, CSF) probability, cortical thickness, cortical surface, and diffusion parameters as well as regional values of these phenotypes for regions of both AAL and FreeSurfer parcellations. For the subjects who underwent FMRI, individual SPM contrast maps for each of the 8 runs were also calculated and included in the database, as well as corresponding BOLD variations in ROIs of the AAL and AICHA atlases, and Wilke's hemispheric functional lateralization index. The BIL\&GIN data sharing is based on a collaborative model.
\end{abstract}




\section{Introduction}

Hemispheric specialization (HS) is a fundamental characteristic of brain large-scale organization, which underpinnings and behavioral correlates are still largely unknown (Hervé et al., 2013, Corballis, 2014). Behavioral and brain asymmetries are indeed common in animals (Bisazza et al., 1998), and humans, in particular, exhibit specific prominent characteristics related to HS, including a high prevalence of right-handedness $(\mathrm{RH})$ and a capacity to acquire language, a function claimed to be predominantly supported by the left hemisphere. Similar to other phenotypes, HS is characterized by between-subject variability as evidenced by the presence of normal individuals having ambilateral or even righthemisphere dominant language representation (Pujol et al., 1999). But the factors explaining this variability are still to be discovered and the relationship between these two prominent characteristics remains under debate (Mazoyer et al., 2014). HS also exists, to various degrees, for other cognitive functions in the motor, visuo-spatial, face, non-verbal communication and emotional processing domains. But the knowledge on their intensities and mutual relationships is sparse and scattered. Advanced anatomical and functional neuroimaging methods coupled to databasing offer strong opportunities for making progress on HS understanding. However, to our knowledge, there has been no endeavor aiming at an organized and multi-dimensional exploration of the behavioral and brain correlates of hemispheric specialization, and of the factors that control their between-subject variability. One reason for this lack is the low prevalence of left-handers in the general population that hampers the recruitment of a large sample of participants balanced for handedness that such an exploration requires (Willems et al., 2014). Another reason is that such exploration requires the design, validation, and adaption to the FMRI environment, of a battery of cognitive tasks dedicated to the investigation of HS different facets. Here, we described a database, named BIL\&GIN (for Brain Imaging of Lateralization by the Groupe d'Imagerie Fonctionnelle) that gathers genetic, behavioral, cognitive, neuroanatomical, and neurofunctional data, in a left-hander (LH) enriched sample of 453 subjects.

\section{What was the BIL\&GIN database designed to do?}

The BIL\&GIN was designed to allow an in-depth exploration of HS and of its variability.

Is it a static set of archived data, or a changing (growing) database?

Raw data acquisition is completed. However, the database is growing, as new phenotypes derived from data processing are included.

\section{What is available?}

\section{How many studies, subjects and imaging modalities are available?}

We recruited 453 young healthy volunteers, balancing for both sex and handedness. Behavioral laterality, and cognitive skills in the language, spatial, and arithmetic domains, were measured in each participant, who also had structural T1 MRI, diffusion tensor imaging (DTI), and resting state functional MRI (rs-FMRI) acquisitions. A subsample of 303 individuals also had 8 runs task-FMRI of a functional battery exploring various aspects of hemispheric specialization for language, visuo-spatial, motor and arithmetic activities. Individuals of this subsample agreed to give a saliva sample for later DNA extraction and genotyping.

\section{What kind of clinical, cognitive, demographic or other phenotypic information is available?}


Basic characteristics of the BIL\&GIN sample of participants are summarized in Table 1. All participants were free of current neuropsychiatric disorders, were not under current medication, and showed no abnormality on their structural brain MRI.

Table 1. Basic characteristics of the BIL\&GIN participants according to selfreported handedness. Note that 2 participants had no eye sighting dominance. FTT: finger tapping test. LH: left-handers; RH: right-handers.

$\begin{array}{llll} & \text { LH } & \text { RH } & \text { All } \\ \text { N } & 205 & 248 & 453 \\ \text { Women (N, \%) } & 100(49 \%) & 132(53 \%) & 232(51 \%) \\ \text { Age (years) } & 25.6 \pm 7.7 & 27.7 \pm 7.7 & 26.8 \pm 7.7 \\ \text { Education (years) } & 14.8 \pm 2.5 & 15.4 \pm 2.5 & 15.1 \pm 2.5 \\ \text { Edinburg Inventory score } & -65.1 \pm 37.9 & 91.8 \pm 14.0 & 20.8 \pm 82.9 \\ \text { FTT asymmetry index (right-left) } & -3.1 \pm 5.2 & 7.2 \pm 5.4 & 2.5 \pm 7.3 \\ \text { Right-eye dominance (N, \%) } & 73(36 \%) & 206(84 \%) & 279(62 \%)\end{array}$

\section{Behavioral laterality measures}

\section{Self reported handedness}

Participants were asked whether they considered themselves as either right-handed, lefthanded, or forced left-handed. Among the 453 participants, 248 considered themselves as right-handers (RH: 116 men and 132 women) and 199 as left-handers (LH: 104 men and 95 women) and 6 as converted right-handers ( 1 man, 5 women), the latter being pooled with the other LH unless otherwise specified. As for the FMRI subsample of 303 subjects, it included 146 RH (72 men and 74 women) and 157 LH ( 82 men and 75 women).

\section{Manual preference strength}

Manual preference strength was evaluated using the Edinburgh inventory score (EI, (Oldfield, 1971), broom item discarded). Scores are shown in Table 1.

\section{Manual skill}

We used the finger-tapping test (FTT, Peters and Durding, 1978) for assessing manual skill. A manual skill asymmetry (FTTasym) was computed as: FTTasym $=($ RFT - LFT $)$, with RFT (resp. LFT) representing the average right (resp. left) index finger tapping score. FTTasym sample average and standard deviation are given in Table 1.

\section{Eye preference}

Eye sighting dominance (ESD) was evaluated by having 451 of the participants extending his arms in front of him, forming a frame using the thumb and index finger of both hands, and 
looking at a distant object through this frame without moving hands, first with both eyes open, then when shutting the left or the right eye. The ESD was that for which the object is perceived at the same place in the frame as with two eyes. ESD occurrences are given in Table 1.

\section{Familial sinistrality}

Positive familial sinistrality (FS +) was defined as the presence of at least one LH individual among participant's first-degree relatives. The proportion of self-reported FS + in the BIL\&GIN was 39\%.

\section{Cognitive skills evaluation}

Table 2 lists the battery of tests that were used for evaluating participant abilities in the language (10 tests), visuo-spatial (5 tests), and arithmetic domains (4 tests). Table 2 also gives the number of subjects that completed each test, as well as the sample mean and standard deviation. 
Table 2. CogBATHS. Battery of cognitive tests performed by the participants of the BIL\&GIN and mean results in the population.

\section{Cognitive battery (unit)}

Verbal skills

Auditory verbal learning test (mean number of recalled words

across 5 repeated lists; max score $=8)($ Rey, 1958)

Auditory phonological learning test (mean number of recalled

pseudo-words across 5 repeated lists; max score $=15$ )

Vocabulary extent $(\max$ score $=44)($ Binois and Pichot, 1956)

Verbal fluency (mean number of verbs generated per item in $10 \mathrm{~s}$ )

Reading span test (span)

Listening span test (span) (Daneman and Carpenter, 1980,

Desmette et al., 1995)

Rhyme judgment $(\max$ score $=80)$

Reading speed (word per minute)

Comprehension threshold (time-compression rate, \%)

Phonological awareness $(\max$ score $=40)$

\section{Visuo-spatial skills}

Mental rotation (max score: 20) (Vandenberg and Kuse, 1978)

Topographic orientation 3D maze

Corsi Block test (visuo-spatial span) (Della Sala et al., 1999)

Spatial attention Cancelation task (Weintraub and Mesulam, 1988)

(Center of Cancellation index, Rorden and Karnath, 2010)

Non-verbal reasoning Raven's matrices (IQ) (Raven, 1956)

$\begin{array}{lll}386 & 108.9 & 10.9\end{array}$

Arithmetic skills

Arithmetical facts $(\max$ score $=36)$

Complex mental calculation $(\max$ score $=8)$

Resolution of linguistic arithmetical problem (max score $=12)$

Finger counting (number of right-starters)
N Mean SD

$\begin{array}{lll}450 & 12.8 \quad 1.6\end{array}$

$\begin{array}{lll}449 & 6.7 \quad 2.3\end{array}$

$\begin{array}{lll}450 & 27.4 \quad 4.2\end{array}$

$\begin{array}{lll}450 & 3.0 & 0.6\end{array}$

$\begin{array}{lll}448 & 3.8 & 1.1\end{array}$

$420 \quad 4.5 \quad 1.1$

$\begin{array}{lll}451 & 66.7 & 6.7\end{array}$

$257 \quad 1290 \quad 315$

$243 \quad 70 \quad 2$

$\begin{array}{lll}386 & 26.5 \quad 7.0\end{array}$ $\begin{array}{lll}385 & 27.3 & 5.7\end{array}$

$\begin{array}{lll}385 & 4.8 & 2.0\end{array}$

$\begin{array}{lll}385 & 8.8 & 1.8\end{array}$

$369166 \quad-$ 


\section{MRI acquisition}

\section{Structural MRI}

The acquisition protocol (30 minute duration) included a high resolution 3D T1-weighted sequence (3D-FFE-TFE; TR $=20 \mathrm{~ms}$; $\mathrm{TE}=4.6 \mathrm{~ms}$; flip angle $=10^{\circ}$; inversion time $=800 \mathrm{~ms}$; turbo field echo factor $=65$; sense factor $=2$; matrix size $=256 \times 256 \times 180 \mathrm{~mm} 3 ; 1 \mathrm{~mm} 3$ isotropic voxel size) and a T2*-weighted multi-slice fast field echo (T2*-FFE; TR $=3500 \mathrm{~ms}$; $\mathrm{TE}=35 \mathrm{~ms}$; flip angle $=90^{\circ}$; sense factor $=2 ; 70$ axial slices; $2 \times 2 \times 2 \mathrm{~mm} 3$ isotropic voxel size).

\section{Diffusion tensor MRI}

Diffusion-weighted imaging (DTI) data were acquired using a single-shot spin-echo echoplanar sequence with 21 non-collinear diffusion gradient directions $(b=1000 \mathrm{~s} / \mathrm{mm} 2)$, the series of 21 directions being acquired twice by reversing the gradients' polarity. Seventy axial slices parallel to the AC-PC plane were acquired from the bottom of the cerebellum to the vertex. Imaging parameters were as follows: $\mathrm{TR}=8500 \mathrm{~ms}, \mathrm{TE}=81 \mathrm{~ms}$, angle $=90^{\circ}$, SENSE reduction factor $=2.5$, FOV $224 \mathrm{~mm}$, acquisition matrix $112 \times 112,2 \times 2 \times 2 \mathrm{~mm} 3$ isotropic voxel. A second series of 42 volumes was acquired leading to a total DTI acquisition time of $15 \min 30 \mathrm{~s}$.

\section{Functional MRI (FMRI)}

Functional images were acquired with a T2*-weighted echo-planar sequence (T2*-EPI; 240 volumes; $\mathrm{TR}=2 \mathrm{~s} ; \mathrm{TE}=35 \mathrm{~ms}$; flip angle $=80^{\circ} ; 31$ axial slices; $3.75 \times 3.75 \times 3.75 \mathrm{~mm} 3$ isotropic voxel size) covering the same field of view as the T2*-FFE acquisition.

\section{Resting state FMRI (rs-FMRI)}

Spontaneous brain activity was monitored while the participants performed an 8-minute resting state (rs) condition. Participants were instructed to "keep their eyes closed, to relax, to refrain from moving, to stay awake, and to let their thoughts come and go". The acquisition was immediately followed by a debriefing interview using ReSQ (Resting state questionnaire Delamillieure et al., 2010) allowing assessment of the participant's spontaneous thought content during the rs-FMRI scanning.

\section{Task-related FMRI (t-FMRI)}

A Functional Battery for Hemispheric Specialization (FunBatHS) exploring HS for language, motor, visuo-spatial, and numerical activities was implemented in a functional MRI environment. Acquisition of FunBatHS FMRI data was organized in two sessions made of 4 runs each, one session being devoted to the mapping of language HS, the other to motor, spatial and numerical skills. Both sessions occurred the same day in a randomized order, each lasting about $2 \mathrm{~h}$. Table 3 summarizes the various runs and tasks of the FunBatHS and Table 4 describes the timing of each of the 8 runs. 
Table 3. FunBATHS. Description of the functional battery of tasks performed by the subjects during the two FMRI sessions.

\begin{tabular}{|c|c|c|c|}
\hline Task name & Stimulus & Instruction & $\begin{array}{l}\text { Reference } \\
\text { task }\end{array}$ \\
\hline $\begin{array}{l}\text { Sentence } \\
\text { production }\end{array}$ & $\begin{array}{l}\text { Line drawing picture of a } \\
\text { scene involving characters }(1 \mathrm{~s} \\
\text { presentation) }\end{array}$ & $\begin{array}{l}\text { Covertly generate a } \\
\text { sentence depicting the } \\
\text { scene during } 9 \mathrm{~s} \text { max }\end{array}$ & $\begin{array}{l}\text { Cross change } \\
\text { detection }\end{array}$ \\
\hline $\begin{array}{l}\text { Word list } \\
\text { production }\end{array}$ & $\begin{array}{l}\text { 1-s presentation of scrambled } \\
\text { line drawing }\end{array}$ & $\begin{array}{l}\text { Covertly generate the } \\
\text { ordered list of months } \\
\text { of the year } 9 \mathrm{~s} \text { max }\end{array}$ & $\begin{array}{l}\text { Cross change } \\
\text { detection }\end{array}$ \\
\hline $\begin{array}{l}\text { Sentence } \\
\text { listening }\end{array}$ & $\begin{array}{l}\text { 1-s presentation of line } \\
\text { drawing picture of a scene } \\
\text { involving characters + spoken } \\
\text { sentence }\end{array}$ & $\begin{array}{l}\text { Listen to } 5 \mathrm{~s} \text { max } \\
\text { sentences }\end{array}$ & $\begin{array}{l}\text { Cross change } \\
\text { detection }\end{array}$ \\
\hline $\begin{array}{l}\text { Word list } \\
\text { listening }\end{array}$ & $\begin{array}{l}\text { 1-s presentation of scramble } \\
\text { drawing + spoken word list }\end{array}$ & $\begin{array}{l}\text { Listen to } 5 \mathrm{~s} \text { max word } \\
\text { list (seasons, days of } \\
\text { the weeks, months of } \\
\text { the year) }\end{array}$ & $\begin{array}{l}\text { Cross change } \\
\text { detection }\end{array}$ \\
\hline $\begin{array}{l}\text { Sentence } \\
\text { reading }\end{array}$ & $\begin{array}{l}\text { 1-s presentation of line } \\
\text { drawing picture of a scene } \\
\text { involving characters + written } \\
\text { sentence }\end{array}$ & Read sentence & $\begin{array}{l}\text { Cross change } \\
\text { detection }\end{array}$ \\
\hline $\begin{array}{l}\text { Word list } \\
\text { reading }\end{array}$ & $\begin{array}{l}\text { 1-s presentation of scramble } \\
\text { drawing + word list }\end{array}$ & $\begin{array}{l}\text { Read word list } \\
\text { (seasons, days of the } \\
\text { weeks, months of the } \\
\text { year) }\end{array}$ & $\begin{array}{l}\text { Cross change } \\
\text { detection }\end{array}$ \\
\hline $\begin{array}{l}\text { Semantic } \\
\text { decision }\end{array}$ & Written words pair & $\begin{array}{l}\text { Judge whether both } \\
\text { words relate to man- } \\
\text { made items }\end{array}$ & $\begin{array}{l}\text { Cross change } \\
\text { detection }\end{array}$ \\
\hline Rhyming & Written pseudo-words pair & $\begin{array}{l}\text { Judge whether both } \\
\text { pseudo-words rhyme }\end{array}$ & $\begin{array}{l}\text { Cross change } \\
\text { detection }\end{array}$ \\
\hline $\begin{array}{l}\text { Right and left } \\
\text { finger tapping } \\
\text { (FT) }\end{array}$ & $\begin{array}{l}\text { Arrow to indicate side of } \\
\text { tapping }\end{array}$ & $\begin{array}{l}\text { Tap left (or right) } \\
\text { finger at internally } \\
\text { guided rhythm (close } \\
\text { to } 2 \mathrm{~Hz} \text { ) }\end{array}$ & $\begin{array}{l}\text { Central cross } \\
\text { fixation }\end{array}$ \\
\hline
\end{tabular}




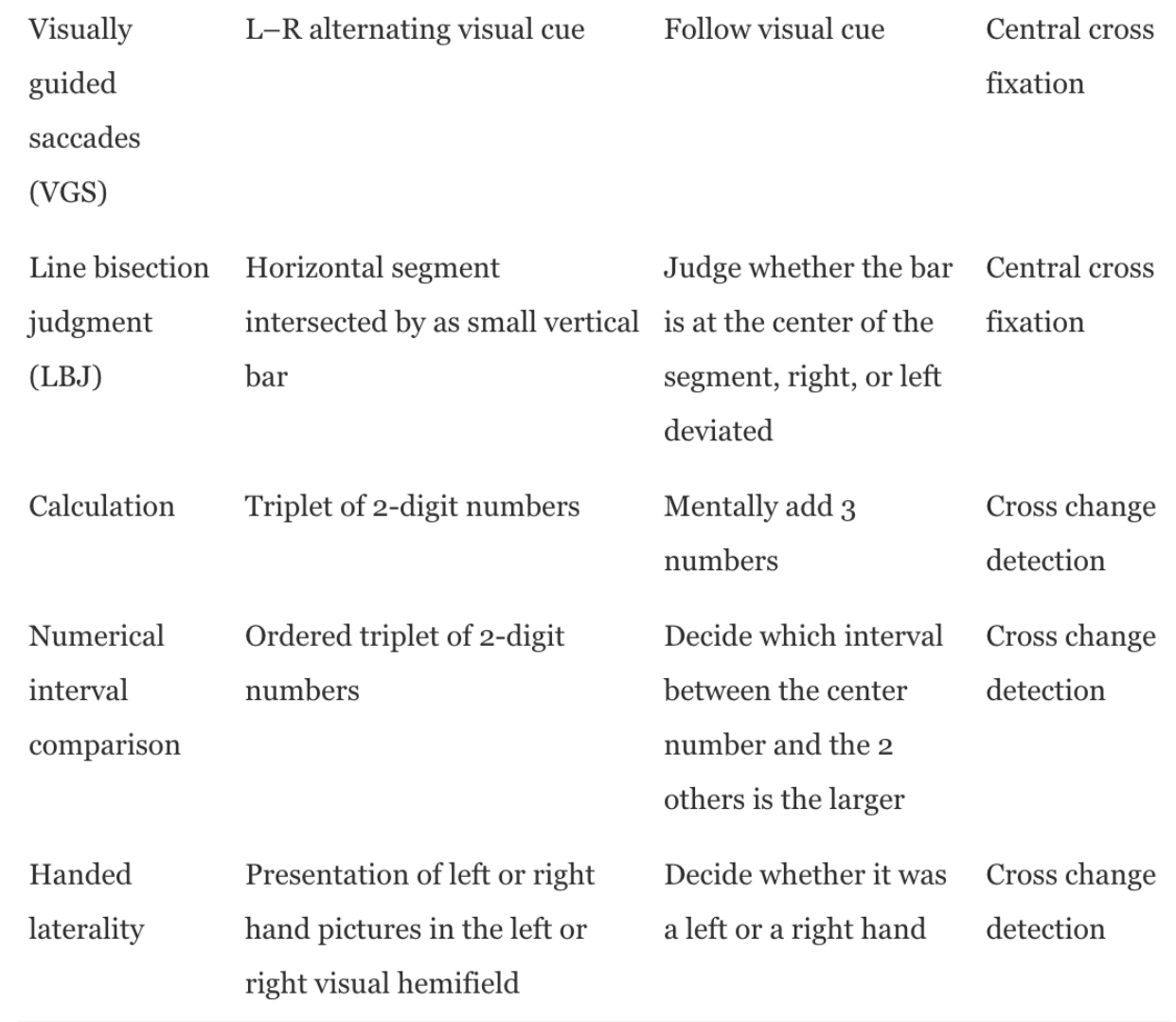


Table 4. Parameters for each run of the FUNBATHS. All runs but the $\# 5$ had an event-related design. Session order and run order within a session were randomized. For the description of reference blocks condition, see Table 3. FT: finger tapping; VGS: visually guided saccades; LBJ: line bisection judgment.

\begin{tabular}{|c|c|c|c|c|c|c|c|c|}
\hline & \multicolumn{4}{|c|}{ Language session } & \multicolumn{4}{|c|}{$\begin{array}{l}\text { Visuo-spatial, motor and numerical } \\
\text { session }\end{array}$} \\
\hline & Run \#1 & Run \#2 & Run \#3 & Run \#4 & Run \#5 & Run \#6 & Run \#7 & Run \# \\
\hline $\begin{array}{l}\text { Run } \\
\text { duration }\end{array}$ & $360 \mathrm{~s}$ & $364 \mathrm{~s}$ & $364 \mathrm{~s}$ & $364 \mathrm{~s}$ & $272 \mathrm{~s}$ & $360 \mathrm{~s}$ & $284 \mathrm{~s}$ & $384 \mathrm{~s}$ \\
\hline Task & $\begin{array}{l}\text { Sentence } \\
\text { \& word list } \\
\text { production }\end{array}$ & $\begin{array}{l}\text { Sentence } \\
\text { \& word } \\
\text { list } \\
\text { listening }\end{array}$ & $\begin{array}{l}\text { Sentence } \\
\text { \& word } \\
\text { list } \\
\text { reading }\end{array}$ & $\begin{array}{l}\text { Semantic \& } \\
\text { rhyming }\end{array}$ & $\begin{array}{l}\text { FT and } \\
\text { VGS }\end{array}$ & LBJ & $\begin{array}{l}\text { Calculation } \\
\text { \& Interval } \\
\text { comparison }\end{array}$ & $\begin{array}{l}\text { Hand } \\
\text { lateral }\end{array}$ \\
\hline $\begin{array}{l}\# \\
\text { events/run }\end{array}$ & $\begin{array}{l}10 \\
\text { sentence } \\
10 \text { word } \\
\text { list }\end{array}$ & $\begin{array}{l}13 \\
\text { sentence } \\
13 \text { word } \\
\text { list }\end{array}$ & $\begin{array}{l}13 \\
\text { sentence } \\
13 \text { word } \\
\text { list }\end{array}$ & $\begin{array}{l}15 \text { rhyming } \\
15 \\
\text { categorization }\end{array}$ & $\begin{array}{l}6 \text { blocks } \\
\text { of FT } \\
\text { ( } 3 / \text { hand) } \\
4 \text { blocks } \\
\text { of VGS }\end{array}$ & $\begin{array}{l}12 \\
\text { R-deviated } \\
12 \\
\text { L-deviated } \\
12 \\
\text { centered }\end{array}$ & $\begin{array}{l}10 \\
\text { calculation } \\
12 \\
\text { comparison }\end{array}$ & $\begin{array}{l}32 \\
\text { (16 pe } \\
\text { hand) }\end{array}$ \\
\hline $\begin{array}{l}\text { Trial } \\
\text { duration }\end{array}$ & $9 \mathrm{~s}$ & $7 \mathrm{~s}$ & $7 \mathrm{~s}$ & $3 s$ & $\begin{array}{l}12 \mathrm{~s} \text { for } \\
\text { FT } \\
16 \mathrm{~s} \text { for } \\
\text { VGS }\end{array}$ & $2 \mathrm{~s}$ & $\begin{array}{l}8 \mathrm{~s} \text { for calc. } \\
5 \mathrm{~s} \text { for } \\
\text { comp. }\end{array}$ & $3 \mathrm{~s}$ \\
\hline $\begin{array}{l}\text { Event } \\
\text { duration }\end{array}$ & $18 \mathrm{~s}$ & $14 \mathrm{~s}$ & $14 \mathrm{~s}$ & $12 \mathrm{~s}$ & n.a. & $10 \mathrm{~s}$ & $\begin{array}{l}14 \mathrm{~s} \text { for } \\
\text { calc. } \\
12 \mathrm{~s} \text { for } \\
\text { comp. }\end{array}$ & $12 \mathrm{~s}$ \\
\hline $\begin{array}{l}\# \\
\text { References }\end{array}$ & 20 & 26 & 26 & 30 & 16 & 36 & 22 & 32 \\
\hline $\begin{array}{l}\text { Reference } \\
\text { task } \\
\text { duration }\end{array}$ & $9 \mathrm{~s}$ & $7 \mathrm{~s}$ & $7 \mathrm{~s}$ & $9 \mathrm{~s}$ & $\begin{array}{l}12 \mathrm{~s} \text { for } \\
\text { FT } \\
16 \mathrm{~s} \text { for } \\
\text { VGS }\end{array}$ & $8 \mathrm{~s}$ & $\begin{array}{l}6 \mathrm{~s} \text { for calc. } \\
7 \mathrm{~s} \text { for } \\
\text { comp. }\end{array}$ & $9 \mathrm{~s}$ \\
\hline
\end{tabular}

\section{FunBatHS: language session}

In the first session, we designed FMRI paradigms to investigate HS for language using different levels of linguistic stimuli, namely pseudo-word, word, and sentence. One run included phonological processing, with a rhyming task on pseudo-words, and semantic processing with a categorization decision on written words. The three other slow event-related runs were designed for the study of production, comprehension, and reading of sentences and lists of words and dealt with comparable stimuli in order to further investigate commonalities' 
and differences across production and comprehension. The word list and sentence stimuli were balanced for number of words, thereby enhancing asymmetries detection (Binder, 2011). In each event of each run, a low-level reference task was included, namely fixation and detection of change of a visual cue.

\section{FunBatHS: motor, spatial and numerical session}

The second session was first devoted to the characterization of HS for spatial processing. We examined HS for spatial attention by both visually guided eye movement and line bisection tasks. Since handedness is a factor influencing HS, we also designed a hand-motor task to measure hand motor functional asymmetries. Finally, we set up three tasks that aimed to question the relationships between different HS. The hand laterality task, where the subjects judged the handedness of a hand presented with various rotation angles, investigating the relationships between motor and spatial HS. Calculation and number interval comparison tasks were designed to study the HS of processing of numbers and its relationship with language and spatial HS. Here again, each run included a low-level reference task (see Table $3)$.

\section{Stimulus delivery and response recording}

Stimuli presentation was programmed in E-prime software (Psychology Software Tools, Pittsburg, PA, USA) embedded in the IFIS-SA system (MRI Devices Inc, Gainesville, FL, USA). Subjects' motor responses were collected using two fiber optic response pads (Current Designs Inc, Philadelphia, PA, USA).

\section{Eye movement tracking}

Eye position was monitored thanks to an infrared eye tracking video system (Mag Design and Engineering, Redwood City, USA; www.magconcept.com, and iViewX'TM MRI-SVTM, SensoMotoric Instruments, Berlin, Germany; www.smi.de).

\section{Practice session and debriefing}

Prior to each session, participants were given a practice version of the tasks on a PC. A postimaging debriefing session was done to collect information on strategies used during each tFMRI run.

\section{Genetic data}

DNA has been extracted from salivary samples (28 $\mu$ g on average, $\mathrm{N}=297$ ). Whole genome re-sequencing in a subset of 29 subjects (Illumina hiseq 2000, × 20 depth) has recently been achieved, thanks to a specific collaborative agreement. Genotyping and/or sequencing are pending additional funds.

\section{What formats do you share the different data types in?}

Tabulated data are shared in spreadsheet format. Imaging data are shared in nifti format.

\section{Does all the data come from one center or scanner?}

MR imaging was performed on the same Philips Achieva 3 Tesla MR scanner and head coil over a time period extending from 2007 to 2011.

\section{Is processed or analyzed data also available, or only raw data?}

As of January 2015, all raw and pre-processed data are stored in the database with the exclusion of genetic data. Pre-processed data are intermediate data states (up the stereotaxic normalization) as described in the MRI pre-processing section. Finalized data are results of 
individual analyses (see MR individual processing). Finalized data are also available for all image types except for DTI that will be included as they become available.

\section{Structural MRI analysis \\ Voxel-based morphometry}

Each participant T1-weighted volume was spatially normalized using a specific cerebral tissue templates built from the T1-weighted images of 80 subjects ( 40 men) acquired with the same scanner and acquisition parameters (Template resolution of $1 \times 1 \times 1 \mathrm{~mm} 3$ voxels; bounding box, $\mathrm{x}=-90$ to $90 \mathrm{~mm}, \mathrm{y}=-126$ to $91 \mathrm{~mm}, \mathrm{z}=-72$ to $109 \mathrm{~mm}$ ) and normalized into the stereotaxic space of the Montreal Neurological Institute (MNI) template. T1 normalized volumes were processed using the SPM5 "segment" procedure with default parameters allowing segmentation of gray matter, white matter and cerebrospinal fluid components for each participant. The total intracranial volume (TIV) was calculated as the sum of the three component volumes.

\section{Surface-based morphometry}

Reconstruction of cortical surfaces and estimation of related structural parameters were performed with the FreeSurfer 5.3.0 package (http://surfer.nmr.mgh.harvard.edu/) that provided 3 local structural phenotypes, namely cortical thickness (CT), cortical surface area (CSA), and cortical surface curvature (CURV). Note that the left hemisphere and right hemispheres were separately processed. Two specific templates were developed in order to perform vertex-wise averaged and asymmetry maps, respectively.

\section{BIL\&GIN surface template}

The CURV parameter was used for driving a non-linear surface-based inter-subject registration procedure that aligned the cortical folding patterns of each subject to a specific surface template (40 individuals, 26 men, 18 right-handers were iteratively aligned together to create the 40-average BIL\&GIN surface representation). Moreover, the CSA resampling included a Jacobian correction accounting for any stretching or compression during the intersubject registration process.

\section{BIL\&GIN symmetric surface template}

We registered the left and right surfaces of the 40 individuals to the left hemisphere of the fsaverage_sym template (fsaverage_sym is the symmetric template provided by the software). We constructed a surface symmetric template by averaging these 80 surfaces. This process was repeated 20 times to remove the influence of the fsaverage_sym-initializing step.

\section{Cortical thickness and surface asymmetries}

Each individual left and right surface was registered to this symmetric template, thereby ensuring that residual sulcal position asymmetries will not bias CT and CSA local asymmetry estimation. Hence, vertex-wise normalized asymmetry index was computed as: $0.5 \times(\mathrm{LH}-$ $\mathrm{RH}) /(\mathrm{LH}+\mathrm{RH}), \mathrm{LH}$ and $\mathrm{RH}$ denoting the left and the right thickness or surface value. The obtained asymmetry maps were then smoothed by a $5 \mathrm{~mm}$ FWHM surface filter.

\section{DTI analysis}

Diffusion-weighted data were separately processed for each participant by combining $t$ FMRIB Software Library (FSL) release 4.0 (www.fmrib.ox.ac.uk/fsl) (Smith et al., 2004) and the command-line tools of Diffusion Toolkit (www.trackvis.org/dtk/).

DTI_gradient_table_creator was used to compute the correct gradient table necessary to calculate diffusion tensors (i.e., for FA, color coded principal eigenvector, fiber tracking etc.) 
for DTI acquisitions on Philips MRI scanners. A 12-parameters affine intra-modal image registration was performed with FLIRT to correct for movement and geometrical deformations (Jenkinson et al., 2002). Diffusion-weighted images with polarity inversion $(2 \times$ 21 volumes) were geometrically averaged (Güllmar et al., 2005). Finally, both series of 42 volumes were arithmetically averaged. The output of dti_recon from the Diffusion Toolkit Package yielded a voxelwise map of fractional anisotropy (FA) for each participant.

\section{FMRI analysis}

The FMRI data were corrected for slice timing differences and motion (6 parameters: 3 translations and 3 rotations) and registered to the T2*-FFE volume. FMRI data were then spatially normalized combining the T2*-FFE to T1-weighted registration matrix and the T1weighted stereotaxic normalization matrix, and smoothed using a Gaussian kernel of $6 \mathrm{~mm}$ full width at half-maximum filter. Finally, using time series for WM, CSF (average time series of voxels belonging to each tissue class), the six motion parameters and the temporal linear trend were regressed out of the fMRI data. Independent Component Analysis (ICA) decomposition (FSL melodic, http://www.fmrib.ox.ac.uk/fsl/) was applied to rs-FMRI data whereas global linear modeling (SPM, http://www.fil.ion.ucl.ac.uk/spm/) was used for processing t-FMRI data. For each participant, contrasts corresponding to each cognitive task versus baseline were computed as well as contrasts between tasks belonging to the same run (as for example sentence minus word list processing) and the corresponding effect of interests-related contrast maps were calculated. Fig. 1 illustrates probabilistic maps of task versus baseline contrasts. 


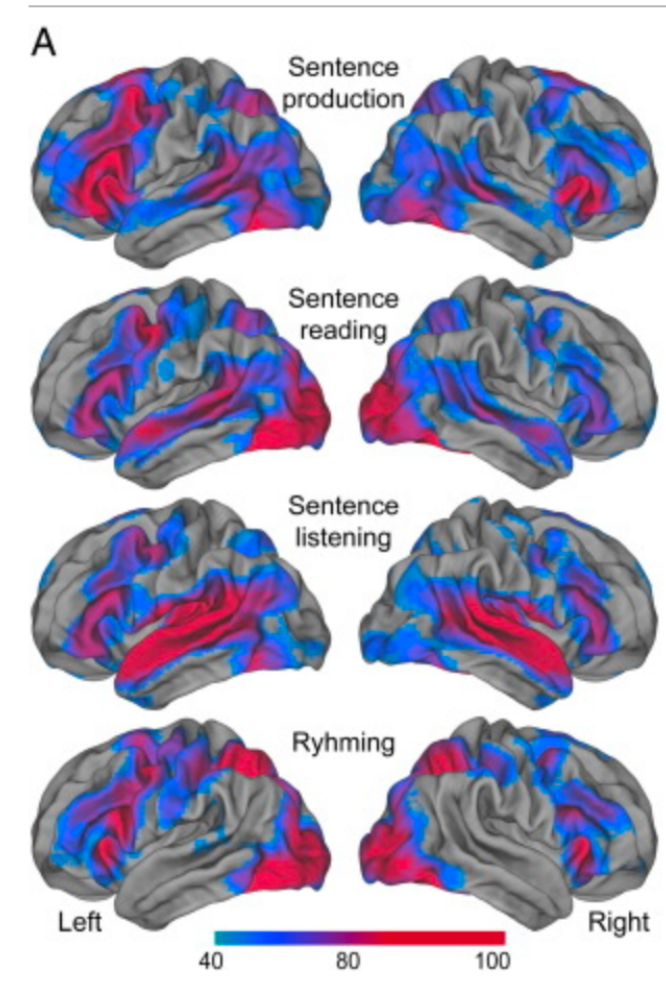

Download : Download high-res image (1MB)

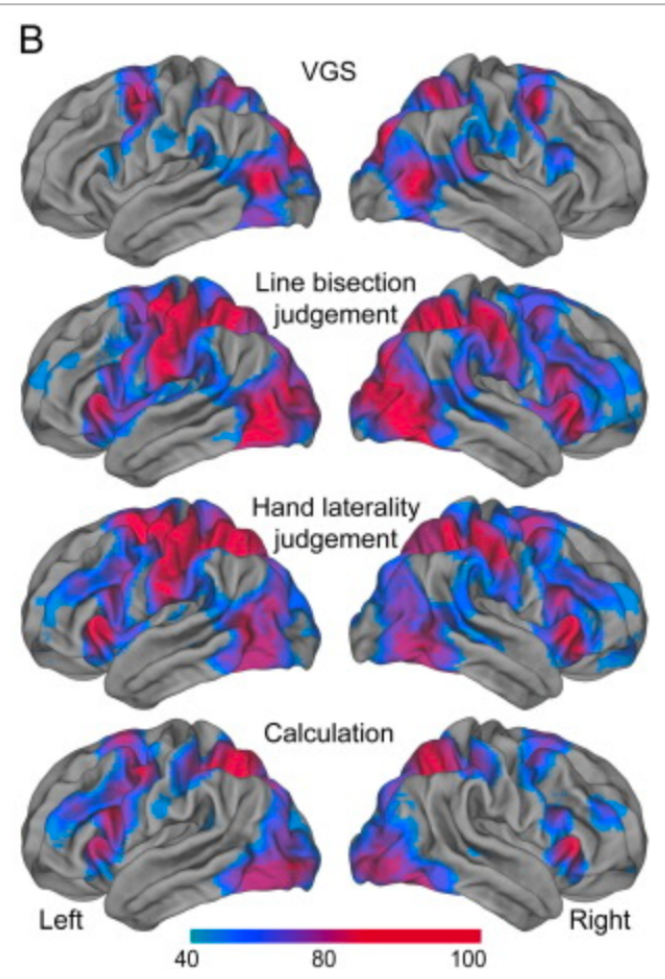

Download : Download full-size image

Fig. 1. Activation probability maps computed on the subsample of right-handed individuals of the BIL\&GIN $(\mathrm{N}=140)$ for various contrasts of the language (panel A) and spatial/numerical (panel B) FMRI sessions. Each probability map is built from individual activation maps using a zero-threshold. Resulting probability maps are displayed using a $40 \%$ lower threshold, i.e., keeping only voxels showing activation in at least $40 \%$ of the sample.

\section{Do the datasets come with citable doi's/uri's?}

\section{No.}

\section{Is imaging or other data quality controlled or reviewed? If so, by whom?}

The quality check was performed for raw, pre-processed, finalized data and results were stored in specific tables. First, consistency between each stored raw data and the corresponding model of acquisition was checked. As regards Freesurfer analysis, because the automatic procedure defining the surface between white and cortical gray matter can lead to errors, an expert examined each axial, sagittal and coronal section of each participant twice for identifying such errors. This led to apply a manually correct the images of 48 individuals that suffered from such artifacts.

For the FMRI pre-processing volume of the BOLD susceptibility artifact and of the subject's movements during each acquisition was quantified. Results of each participant, and each of the contrast maps were visually inspected, checking the absence of artifacts related to insufficient movement correction or to field inhomogeneity. Table 5 describes the number of excluded subjects per FunBatHS run for the 300 remaining subjects. 
Table 5. Description of the number of run exclusion for the FunBatHS.

\begin{tabular}{lll} 
Task name & Number of excluded subjects & Final number of subjects \\
\hline Sentence production & 3 & 297 \\
Word list production & 1 & 299 \\
Sentence listening & 0 & 300 \\
Word list listening & o & 300 \\
Sentence reading & 2 & 298 \\
Word list reading & 2 & 298 \\
Semantic decision & 2 & 298 \\
Rhyming & 2 & 298 \\
Right and left finger tapping (FT) & 8 & 292 \\
Visually guided saccades (VGS) & 3 & 297 \\
Line bisection judgment (LBJ) & 3 & 297 \\
Calculation & 4 & $262^{\mathrm{a}}$ \\
Numerical interval comparison & 2 & $264^{\mathrm{a}}$ \\
Hand laterality & 4 & 296 \\
\hline & & \\
& &
\end{tabular}

a

Note that only 266 subjects performed calculation and numerical interval comparison runs.

\section{How can people access the data?}

Is it open to everyone (or only those with specifically validated identities)? Is there a registration process?

The BIL\&GIN is not freely available and its content cannot be immediately downloaded. Rather, we have implemented a data-sharing model based on collaborative research agreements. Request for joint research projects can be made through the BIL\&GIN website (http://www.gin.cnrs.fr/BIL\&GIN) or by email to the corresponding author of the present paper.

Are there data usage agreements required for access and if so how are they handled? Collaborative research agreements on BIL\&GIN data usage usually include publication coauthorship of publication and cost sharing whenever additional laboratory work is needed.

What were the needs of the repository that it was set up that way?

As the BIL\&GIN was acquired without support from national or international research agencies, the owners of the database have control on the way it is distributed. Their decision was that collaborative agreements would be the optimal way of valorizing their work.

Is there a system for updating users if data is withdrawn/revised/added to? 
Database content is upgraded, as additional phenotypes issued from data processing are available. Potential users are informed through the database website

(http://www.gin.cnrs.fr/BIL\&GIN).

What is the design architecture/system for handling large data request downloads, interrupted connections, etc.?

The data management system, called the GINdb (Joliot et al., 2010, Fig. 2), is based on MySQL (http://www.mysql.com) and is linked to processing software through 3 interfaces (Matlab $\subset$, Apache (http://apache.org), ODBC (http://www.mysql.com)). All data (raw, preprocessed and finalized) included in the GINdb were tagged through models including a textual description and the essential parameters characterizing the data.

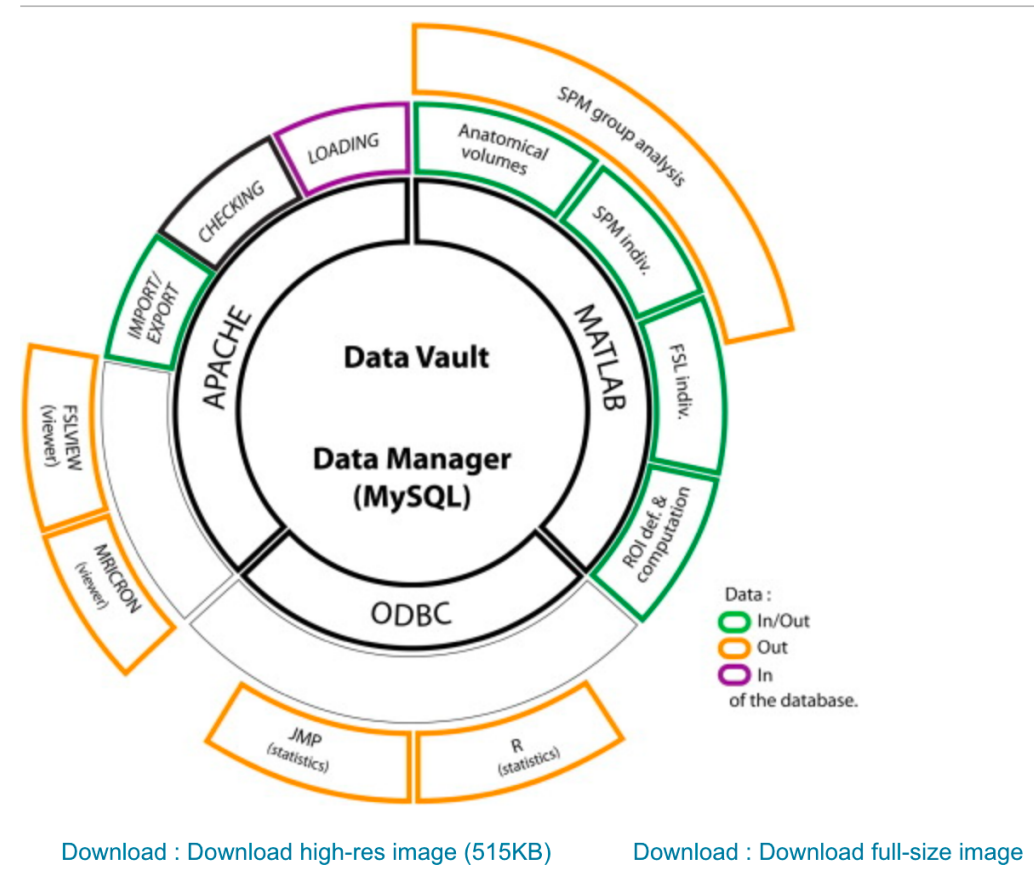

\begin{abstract}
Fig. 2. GIN $\mathrm{db}_{\mathrm{db}}$, the BIL\&GIN management system. Management of the database is organized in 3 layers. The core of $\mathrm{Gin}_{\mathrm{db}}$ is based on MySQL (http://www.mysql.com) and is linked to the software through a 1st layer made of 3 interfaces namely Matlab@), Apache (http://apache.org), and ODBC (http://www.mysql.com). A 2nd layer includes the software that accesses the database, while a 3 rd layer concerns software interfaced for group-level statistical analysis (SPM, JMPC , R (http://cran.r-project.org)) and visualization purposes (MRicron, http://www.sph.sc.edu/comd/rorden/MRicron).
\end{abstract}

Can anybody contribute new data? What are the requirements on new data?

Raw data acquisition is completed. Database expansion is by adding new phenotypes derived from raw data processing.

What are the long-term plans for managing and maintaining this resource?

Maintenance and access to the BIL\&GIN will be sustained on long term.

\title{
Acknowledgments
}

The authors are indebted to MR Turbelin and F Lamberton for their contribution in data acquisition and management. 


\section{References}

J.R. Binder Functional MRI is a valid noninvasive alternative to Wada testing. Epilepsy Behav., 20 (2011), pp. 214-222

D.R. Binois, D.P. Pichot Test de vocabulaire: manuel d'application ; Editions du Centre de psychologie appliquée (1956)

A. Bisazza, L.J. Rogers, G. Vallortigara The origins of cerebral asymmetry: a review of evidence of behavioural and brain lateralization in fishes, reptiles and amphibians.

Neurosci. Biobehav. Rev., 22 (1998), pp. 411-426

M.C. Corballis Left brain, right brain: facts and fantasies; PLoS Biol., 12 (2014), p. e1001767

M. Daneman, P.A. Carpenter Individual differences in working memory and reading. J. Verbal Learn. Verbal Behav., 19 (1980), pp. 450-466

P. Delamillieure, G. Doucet, B. Mazoyer, M.R. Turbelin, N. Delcroix, E. Mellet, L. Zago, F. Crivello, L. Petit, N. Tzourio-Mazoyer, M. Joliot The resting state questionnaire: an introspective questionnaire for evaluation of inner experience during the conscious resting state. Brain Res. Bull., 81 (2010), pp. 565-573

S. Della Sala, C. Gray, A. Baddeley, N. Allamano, L. Wilson Pattern span: a tool for unwelding visuo-spatial memory. Neuropsychologia, 37 (1999), pp. 1189-1199

D. Desmette, M. Hupet, M.-A. Schelstraete, M. Van der Linden Adaptation en langue française du « Reading Span Test » de Daneman et Carpenter (1980). Année Psychol., 95 (1995), pp. 459-482

D. Güllmar, J. Haueisen, J.R. Reichenbach Analysis of b-value calculations in diffusion weighted and diffusion tensor imaging. Concepts Magn. Reson. Part A, 25 (2005), pp. 53 66

P.Y. Hervé, L. Zago, L. Petit, B. Mazoyer, N. Tzourio-Mazoyer Revisiting hemispheric specialization with neuroimaging. TICS, 17 (2013), pp. 69-80

M. Jenkinson, P. Bannister, M. Brady, S. Smith Improved optimization for the robust and accurate linear registration and motion correction of brain images. Neuroimage, 17 (2002), pp. 825-841

M. Joliot, N. Delcroix, L. Zago, M. Vigneau, F. Crivello, G. Simon, L. Petit, M.R. Turbelin, M. Naveau, F. Lamberton, P.Y. Herve, G. Jobard, E. Mellet, B. Mazoyer, N. TzourioMazoyer GINdb: architecture of a protable database for the storage and processing of human functional brain imaging experimental data. 16th Annual Meeting of the Organization for Human Brain Mapping, Barcelona, Spain, Abstract \#932 (2010)

B. Mazoyer, L. Zago, G. Jobard, F. Crivello, M. Joliot, G. Perchey, E. Mellet, L. Petit, N. Tzourio-Mazoyer Gaussian mixture modeling of hemispheric lateralization for language 
in a large sample of healthy individuals balanced for handedness. PLoS One, 9 (2014), p. e101165

R.C. Oldfield The assessment and analysis of handedness: the Edinburgh inventory. Neuropsychologia, 9 (1971), pp. 97-113

M. Peters, B.M. Durding Handedness measured by finger tapping: a continuous variable. Can. J. Psychol., 32 (1978), pp. 257-261

J. Pujol, J. Deus, J.M. Losilla, A. Capdevila Cerebral lateralization of language in normal left-handed people studied by functional MRI. Neurol, 52 (1999), p. 1038-1038

J.C. Raven The principle of individuation and the co-ordinates of conduct. Br. J. Psychol., 47 (1956), pp. 95-100

A. Rey Mémorisation d'une série de 15 mots en 5 répétitions. A. Rey (Ed.), L'Examen Clinique en Psychologie, Presses Universitaires de France, Paris (1958)

C. Rorden, H.O. Karnath A simple measure of neglect severity. Neuropsychologia, 48 (2010), pp. 2758-2763

S.M. Smith, M. Jenkinson, M.W. Woolrich, C.F. Beckmann, T.E. Behrens, H. Johansen-Berg, P.R. Bannister, M. De Luca, I. Drobnjak, D.E. Flitney Advances in functional and structural MR image analysis and implementation as FSL. Neuroimage, 23 (2004), pp. S208-S219

S.G. Vandenberg, A.R. Kuse Mental rotations, a group test of three-dimensional spatial visualization. Percept. Motor Skills, 47 (1978), pp. 599-604

S. Weintraub, M.M. Mesulam Visual hemispatial inattention: stimulus parameters and exploratory strategies. J. Neurol. Neurosurg. Psychiatry, 51 (1988), pp. 1481-1488

R.M. Willems, L. Van der Haegen, S.E. Fisher, C. Francks On the other hand: including left-handers in cognitive neuroscience and neurogenetics. Nat. Rev. Neurosci., 15 (2014), pp. 193-201 